\title{
28 Research Square \\ Mapping the Forest Fire Risk Zones Using Artificial Intelligence with Risk Factors Data
}

\section{Volkan Sevinç ( $\nabla$ vsevinc@mu.edu.tr)}

Mugla Sitki Kocman University Faculty of Science: Mugla Sitki Kocman Universitesi Fen Fakultesi https://orcid.org/0000-0003-4643-443X

\section{Research Article}

Keywords: Forest fire risk zone map, forest fires, k-means algorithm, artificial intelligence

Posted Date: January 3rd, 2022

DOI: https://doi.org/10.21203/rs.3.rs-1130891/v1

License: (c) (1) This work is licensed under a Creative Commons Attribution 4.0 International License. Read Full License

Version of Record: A version of this preprint was published at Environmental Science and Pollution Research on August 16th, 2022. See the published version at https://doi.org/10.1007/s11356-022-22515W. 


\section{Abstract}

Geographical information system data has been used in forest fire risk zone mapping studies commonly. However, forest fires are caused by many factors, which cannot be explained only by geographical and meteorological reasons. Human-induced factors also play an important role in occurrence of forest fires and these factors depend on various social and economic conditions. This article aims to prepare a fire risk zone map by using a data set consisting of nine human-induced factors, three natural factors, and a temperature factor causing forest fires. Moreover, an artificial intelligence method, k-means, clustering algorithm was employed in preparation of the fire risk zone map. Turkey was selected as the study area as there are social and economic varieties among its zones. Therefore, the forestry zones in Turkey were separated into three groups as low, moderate, and high-risk categories and a map was provided for these risk zones. The map reveals that the forestry zones on the west coast of Turkey are under high risk of forest fire while the moderate risk zones mostly exist in the southeastern zones. The zones located in the interior parts, in the east, and on the north coast of Turkey have comparatively lower forest fire risks.

\section{Introduction}

Forests are important habitats for an ecologically and economically sustainable life. Therefore, it is important to take precautions against various factors damaging the forests. One of the factors that harm the forests is forest fires. Forest fires arise for some natural or unnatural reasons. In order to prevent the forest fires, risk zones maps are useful to take the necessary precautions in accordance with the corresponding risk factors.

In literature, there are plenty of studies concerning forest fire risk mapping. However, vast majority of these studies use Global Information System (GIS) and remote sensing to prepare these maps. Among these studies, Jaiswal et al. (2002) prepared a forest zones risk map for Gorna Subwatershed in India. Erten et al. (2004) prepared a forest fire risk zone map for Gallipoli area in Turkey by using satellite imagery and GIS data. Dong et al. (2005) provide a forest fire risk zone map with the help of GIS data for Baihe forestry bureau in China. Xu et al. (2006) mapped the forest fire risk zones using spatial data with the help of principal component analysis for Baihe Forestry Bureau in Jilin Province of China. Bahadır (2010) prepared a forest fire risk zone map of Turkey based on GIS data. Nişancı et al. (2010) prepared a fire density map in Trabzon province of Turkey using GIS data. Ghobadi et al. (2012) prepared a forest fire risk zone map using GIS for northern forests of Iran. Sharma et al. (2012) employed fuzzy analytic hierarchy process (AHP) techniques for forest fire risk modeling in India. Karabulut et al. (2013) determined the forest fire risk zones in Kahramanmaraş province of Turkey by using GIS data. Mohammadi et al. (2014) also employed a logistic regression model along with GIS for forest fire risk zone modeling in Iran. Sivrikaya et al. (2014) prepared a forest fire risk map of Turkey based on GIS data. Bingöl (2017) determined the forest fire risk zones in Burdur province of Turkey with GIS data. Pandey and Gosh (2018) generated a fire risk model to map the fire risks using remote sensing and GIS technique, in Pauri Garwhal District, India. Yathish et al. (2019), however, built a logistic regression model to make a comparative analysis of forest fire risk zone mapping methods also considering the expert 
knowledge. Gülçin and Deniz (2020) performed a forest fire risk zone mapping study depending on GIS data in Manisa province of Turkey.

The objective of this study is to prepare a fire risk zone map with an artificial intelligence method, $k$ means algorithm, as well as using a data set consisting of the variables including human-induced factors, natural factors, and a temperature factor causing forest fires.

In the article, the research gap and the motivation of the study are provided in the next section. Afterwards, information about k-means clustering algorithm with its steps and flowchart is provided in the second section. In the third section, the area of study is introduced and the variables used in the study are given with their explanations. Then, in the fourth section, the prepared forest fire risk zone map of Turkey is provided with the risk levels and the corresponding zones. Moreover, various comments about the fire risk zones, some possible reasons for their risk levels, and some differences among these zones are presented. Finally, some general conclusions are provided in the fifth section.

\subsection{Research gap and motivation of the study}

In the literature, the studies concerning forest fire risk zone mapping depend on the GIS and remote sensing data. However, forest fires are caused by many factors, which cannot be explained only by geographical and meteorological factors. Human-induced factors also play an important role in occurrence of forest fires and human-induced factors depend on various social, cultural, and economic conditions.

The novelty of our study is that unlike the forest fire zone mapping studies depending on GIS or remote sensing data, our study uses a new approach to forest fire risk zone mapping, which depends on various human-induced or natural factors causing forest fires and temperature. Moreover, we use an artificial intelligence method, k-means clustering algorithm to prepare the forest fire risk zone map.

Turkey is frequently subjected to forest fires. However, the characteristics of the forest fires are different in the different regions of Turkey. There are also social, cultural, and economic varieties among these regions. Thus, Turkey was chosen as the area of study to be able to include the different levels of the forest fire factors belonging to different zones. Finally, a forest fire risk zone map of Turkey, which depends on nine human-induced forest fire factors as well as three natural factors and a temperature factor, was prepared.

\section{Materials And Methods}

Estimation approaches that are based on artificial intelligence build highly successful results by eliminating a number of disadvantages of the traditional approaches. Machine learning is a branch of artificial intelligence and there are various machine learning algorithms for different purposes such as classification, clustering, and association. $\mathrm{K}$-means is a machine learning algorithm, which is used for clustering analysis. 


\subsection{K-means clustering algorithm}

Clustering analysis is a multivariate statistical method. In the clustering analysis, the aim is to make variables with similar features in a data set to make the variables to create a set of clusters. Various features hidden in large data sets can be revealed with clustering analysis. In clustering analysis, there are two main approaches as hierarchical and non-hierarchical clustering. In the hierarchical clustering analysis, there is no prior information about the number of clusters in the data set and therefore, initially, each observation is assumed to be a cluster. Then, the cluster merge operations are carried out depending on the smallest distance between the cluster centers and this process is continued until the distances are optimally distributed among the clusters.

In non-hierarchical clustering analysis, the number of clusters $\mathrm{k}$ is known or predetermined. K-means clustering is a non-hierarchical clustering algorithm. Each observation in k-means algorithm can only belong to one cluster. K-means algorithm initially determines the randomly selected $\mathrm{k}$ cluster center points. At the beginning, the randomly selected cluster center points are randomly selected observations. Afterwards, by assigning the other points to the closest center points, initial clusters are formed. After this process, cluster center points are re-calculated and new clusters are formed by assigning the least distant points to the new clusters. This process continues until the central points of the sets do not change. In order to calculate the distances, there are some measures such as Euclidian, Manhattan, Canberra, maximum value Distance, Minkowski, and Mahalanobis distances. Let $X_{i}$ and $Y_{i}$ denote two data points in a data set and $d$ denote the distance between $X_{i}$ and $Y_{i}$. Let $S$ denote the covariance matrix. Then, Euclidian, Manhattan, Canberra, Minkowski, and Mahalanobis distances can be calculated using the formulas given in Eq. 1, 2, 3, 4, and 5 respectively.

$$
\text { Euclidiandistance }=\sqrt{\sum_{i=1}^{n}\left(X_{i}-Y_{i}\right)^{2}}
$$

$$
\text { Manhattandistance }=\sum_{i=1}^{n}\left|X_{i}-Y_{i}\right|
$$

$$
\text { Canberradistance }=\sum_{i=1}^{n} \frac{\left|X_{i}-Y_{i}\right|}{\left|X_{i}\right|+\left|Y_{i}\right|}
$$




$$
\text { Minkowskidistance }=\left[\sum_{i=1}^{n}\left(\left|X_{i}-Y_{i}\right|\right)^{p}\right]^{1 / p}
$$

$$
\text { Mahalanobisdistance }=\sqrt{\left(X_{i}-Y_{i}\right)^{T} S^{-1}\left(X_{i}-Y_{i}\right)}
$$

5

The steps of the k-means clustering algorithm can be summarized as follows.

i. The number of clusters, $k$, is decided.

ii. $k$ observations are selected from the data set randomly and these values are assumed to be the initial clusters and their centers.

iii. Each observation is assigned to the closest center point and new clusters are formed.

iv. Cluster centers are re-calculated.

v. If the new cluster centers are the same as the previous ones, the clustering process is stopped; if not, the process is continued from step iii.

The steps of the k-means algorithm given above can also be visualized by a flowchart. The flowchart of the k-means clustering algorithm is provided in Figure 1.

\section{Study Area And Data}

In Turkey, state forests are owned and controlled by Orman Genel Müdürlüğü (General Directorate of Forestry - GDF), which is a government agency. The study area was chosen to be the 28 GDF zones in Turkey, which are Adana, Amasya, Ankara, Antalya, Artvin, Balıkesir, Bolu, Bursa, Çanakkale, Denizli, Elazığ, Erzurum, Eskişehir, Giresun, Isparta, İstanbul, İzmir, Kahramanmaraş, Kastamonu, Kayseri, Konya, Kütahya, Mersin, Muğla, Sakarya, Şanlıurfa, Trabzon, and Zonguldak zones. Figure 2 shows the GDF zones in Turkey.

The data used in the study were derived from the forestry statistics collected and published by the GDF (2021) for the years 2007-2019. The data set consists of the amount of burning forest areas (ha) depending on various forest fire causes and temperature. The forest fire causes existing in the data set can be listed as temperature, stubble fire, dump fire, hunting, shepherd fire, cigarette fire, picnic fire, terror, arson, expanding, energy lines, traffic accidents, lightning reasons. It can be seen that, among the known reasons, all are human-induced factors except for temperature, energy lines (broken due to wind etc.), and lightning. The variables and their definitions are briefly presented in Table 1. 
Table 1

The variables used in the study

$\begin{array}{ll}\text { Variables } & \text { Definitions } \\ \text { GDF zones } & \begin{array}{l}\text { The General Directorate of Forestry zones in Turkey, which are Adana, Amasya, } \\ \text { Ankara, Antalya, Artvin, Balıkesir, Bolu, Bursa, Çanakkale, Denizli, Elazı̆g, Erzurum, }\end{array} \\ & \begin{array}{l}\text { Eskişehir, Giresun, Isparta, Istanbul, Izmir, Kahramanmaraş, Kastamonu, Kayseri, } \\ \text { Konya, Kütahya, Mersin, Muğla, Sakarya, Şanlıurfa, Trabzon, and Zonguldak zones }\end{array}\end{array}$

Temperature The average temperature measured at the time the forest fire started $\left({ }^{\circ} \mathrm{C}\right)$

Stubble fire The amounts of areas burned in forest fires induced by the fires that are made to burn the stubbles (ha)

Dump fire The amounts of areas burned in forest fires induced by the fires starting in dump areas (ha)

Hunting The amounts of areas burned in forest fires induced by the gun fires during hunting (ha)

Shepherd The amounts of areas burned in forest fires induced by the fires that are made by fire shepherds for heating or cooking purposes (ha)

Cigarette fire The amounts of areas burned in forest fires induced by cigarettes thrown without being extinguished (ha)

Picnic fire The amounts of areas burned in forest fires induced by picnic fires (ha)

Terror The amounts of areas burned in forest fires induced by the fires made for terror purposes (ha)

Arson The amounts of areas burned in forest fires induced by people for the purpose of arson (ha)

Expanding The amounts of areas burned in forest fires caused by people to expand their lands into forests (ha)

Energy lines The amounts of areas burned in forest fires induced by the sparks from broken energy lines (ha)

Traffic The amounts of areas burned in forest fires induced by traffic accidents (ha) accidents

Lightning The amounts of areas burned in forest fires induced by lightning (ha)

Figure 3 shows the amounts of burned forest areas (ha) depending on various causes in the GDF zones of Turkey.

When the patterns in Figure 3 are examined, highest amounts of burned areas are seen in Antalya, Balıkesir, Çanakkale, İzmir, Kahramanmaraş, Muğla, and Şanlıurfa zones. The most harmful factors appear to be lightning and stubble fire. Unlike other zones, energy lines seem to be an extremely harmful forest fire factor in Antalya zone. Additionally, arson-induced forest fires are seen more frequently in Kahramanmaraş zone. 


\section{Results And Discussion}

In order to prepare the forest fire risk zone map of Turkey based on k-means clustering algorithm, Knime (2021) software was employed. The GDF zones were separated into three groups as high, moderate, and low risk zones. The forest fire risk groups and the corresponding GDF zones in Turkey are provided in Table 2.

Table 2

Forest fire risk groups of the General Directorate of Forestry zones of Turkey

\begin{tabular}{|c|c|c|}
\hline High Risk Zones & Moderate Risk Zones & Low Risk Zones \\
\hline Çanakkale & Adana & Amasya \\
\hline İzmir & Antalya & Ankara \\
\hline \multirow[t]{18}{*}{ Muğla } & Balıkesir & Artvin \\
\hline & Kahramanmaraş & Bolu \\
\hline & Şanlıurfa & Bursa \\
\hline & & Denizli \\
\hline & & Elazığ \\
\hline & & Erzurum \\
\hline & & Eskişehir \\
\hline & & Giresun \\
\hline & & Isparta \\
\hline & & İstanbul \\
\hline & & Kastamonu \\
\hline & & Kayseri \\
\hline & & Konya \\
\hline & & Kütahya \\
\hline & & Mersin \\
\hline & & Sakarya \\
\hline & & Trabzon \\
\hline & & Zonguldak \\
\hline
\end{tabular}

Using the risk zone groups provided in Table 2, it is possible to prepare the forest fire risk zone map of Turkey. The map of the forest fire risk groups and the corresponding GDF zones are presented in Figure 4. 
When the forest fire risk zone map of Turkey presented in Figure 4 is examined, it is seen that the high-risk zones exist on the west coast of Turkey. Çanakkale, İzmir, and Muğla zones have the highest forest fire risks. This result can be explained by various reasons. First of all, the temperatures in these zones are comparatively higher especially in summer seasons. Secondly, these regions are touristic and highly populated zones, which leads to an increase in the number of human-induced forest fires.

As far as the zones on the south coast of Turkey are considered, however, Antalya, Adana, and Kahramanmaraş zones seem to have moderate levels of fire risks. Similarly, the inner parts of Kahramanmaraş zone and Şanlıurfa, which cover the most parts of the southeast of Turkey, appear to have moderate levels of fire risks. Although Mersin zone exist on the Mediterranean coast of Turkey, it appeared to be a low risk zone. This difference can be explained by one of the economic characteristics of Mersin. Unlike the zones on the west coast of Turkey, there are not high densities of touristic settlements and movements in Mersin. Thus, this property of Mersin may be a factor reducing the human-induced forest fires compared to the touristic zones. The zones in the inner parts, the zones on the north coast, and the zones in the eastern parts of Turkey were found to have low levels of forest fire risks. The low level of forest fire risks in the northern zones of Turkey can be explained by the seasonal properties. In the northern parts of Turkey, the temperatures are comparatively low and there is plenty of rain observed all year long. In the eastern part, the lower forest fire risks may be due to the high altitudes of this region, which causes comparatively lower temperatures. Moreover, population density in the eastern part is less dense than the western parts, which may be another reason reducing the risk of human-induced forest fires.

When the forest fire risk zone map of Turkey in our study, which is based on k-means algorithm, and the one provided by Bahadır (2010) are compared, it can be seen that there are similarities between the two maps. The map given by Bahadır (2010) indicates that İzmir is a very high-risk zone. Moreover, Muğla and Balıkesir are partly high-risk zones. These results are partly consistent with the results of our map, which indicates that İzmir and Muğla are zones with high forest fire risk while Balıkesir zone has a moderate level of risk. Bahadır (2010) labels Antalya as a zone with a very high risk. However, Antalya appears to be a moderate level of risk zone in our map. Bahadır (2010) also classifies some parts of Adana and Kahramanmaraş zones as high or very high-risk zones. However, both Adana and Kahramanmaraş zones are labeled as moderate risk zones. These differences can be explained by the changes in various conditions such as population, climate, and precautions taken in the past 11 years.

\section{Conclusions}

In conclusion, in this study, a forest fire risk zone map for Turkey is prepared. It is seen that the forest fire risk zone maps existing in the literature were all prepared by using GIS data and remote sensing. However, the map provided in this study was prepared differently, by using various forest fire risk factors and an artificial intelligence method, k-means clustering algorithm. Finally, it was seen that the forest fire risk zone map of Turkey based on artificial intelligence and the risk factors gave quite consistent results with the maps prepared by using GIS and remote sensing data. The riskiest zones in Turkey in terms of forest 
fires appeared to be the ones in the western region, while the less risky zones are in the northern and eastern regions. As a continuation of this study, other forest fire risk maps can be prepared for local zones or for other countries by using the same or different risk factors with appropriate artificial intelligence methods.

\section{Declarations}

Ethical Approval:This article does not contain any studies with human participants or animals performed by the author.

Consent to Participate:The sole author of the manuscript consents to participate.

Consent to Publish:The sole author of the manuscript consents to publish.

Authors Contributions:All of the study, conception, and design of the manuscript belong to Volkan Sevinç, the sole author of the manuscript.

Funding: This study was not funded by anyone or any establishment.

Competing Interests: The sole author of this manuscript declares that he has no conflict of interest.

Availability of data and materials: The data can be shared on a reasonable request.

\section{References}

1. Bahadır, M. (2010). Türkiye’de (1998-2007) Görülen Orman Yangınlarının Yüzey ve Rakamsal Sorgulama analizi. Nature Sciences, 5(3), 146-162.

2. Bingöl, B. (2017). Determination of forest fire risk areas in Burdur Province using Geographical Information Systems. Turkish Journal of Forest Science, 1(2), 169-182.

3. Dong, X. U., Li-min, D., Guo-fan, S., Lei, T., \& Hui, W. (2005). Forest fire risk zone mapping from satellite images and GIS for Baihe Forestry Bureau, Jilin, China. Journal of forestry research, 16(3), 169-174.

4. Erten, E., Kurgun, V., \& Musaoglu, N. (2004, July). Forest fire risk zone mapping from satellite imagery and GIS: a case study. In XXth Congress of the International Society for Photogrammetry and Remote Sensing, Istanbul, Turkey (pp. 222-230).

5. GDF (2021). https://www.ogm.gov.tr/tr/ormanlarimiz/resmi-istatistikler

6. Ghobadi, G. J., Gholizadeh, B., \& Dashliburun, O. M. (2012). Forest fire risk zone mapping from geographic information system in Northern Forests of Iran (Case study, Golestan province). International Journal of Agriculture and Crop Sciences, 4(12), 818-824.

7. Gülçin, D., \& Deniz, B. (2020). Remote sensing and GIS-based forest fire risk zone mapping: The case of Manisa, Turkey. Türkiye Ormancılık Dergisi, 21(1), 15-24. 
8. Jaiswal, R. K., Mukherjee, S., Raju, K. D., \& Saxena, R. (2002). Forest fire risk zone mapping from satellite imagery and GIS. International Journal of Applied Earth Observation and Geoinformation, 4(1), 1-10.

9. Karabulut, M., Karakoc, A., Gurbuz, M., \& Kizilelma, Y. (2013). Determination of forest fire risk areas using geographical information systems in Baskonus Mountain (Kahramanmaras). The Journal of International Social Research, 6(24), 171-179.

10. Knime (2021). https://www.knime.com/

11. Mohammadi, F., Bavaghar, M. P., \& Shabanian, N. (2014). Forest fire risk zone modeling using logistic regression and GIS: an Iranian case study. Small-scale Forestry, 13(1), 117-125.

12. Nişancı, R., Yıldıım, V., \&Çolak, H. E. (2010). Coğrafı bilgi sistem uygulamaları. Bilim ve Teknik, 514, 58-63.

13. Pandey, K., \& Ghosh, S. K. (2018). Modelling of Parameters for Forest Fire Risk Zone Mapping. ISPRSInternational Archives of the Photogrammetry, Remote Sensing and Spatial Information Sciences, 42(5), 299-304.

14. Sharma, L. K., Kanga, S., Nathawat, M. S., Sinha, S., \& Pandey, P. C. (2012). Fuzzy AHP for forest fire risk modeling. Disaster Prevention and Management: An International Journal.

15. Sivrikaya, F., Sağlam, B., Akay, A. E., \& Bozali, N. (2014). Evaluation of forest fire risk with GIS. Polish Journal of Environmental Studies, 23(1).

16. Xu, D., Shao, G., Dai, L., Hao, Z., Tang, L., \& Wang, H. (2006). Mapping forest fire risk zones with spatial data and principal component analysis. Science in China Series E: Technological Sciences, 49(1), 140-149.

17. Yathish, H., Athira, K. V., Preethi, K., Pruthviraj, U., \& Shetty, A. (2019). A Comparative Analysis of Forest Fire Risk Zone Mapping Methods with Expert Knowledge. Journal of the Indian Society of Remote Sensing, 47(12), 2047-2060.

\section{Figures}




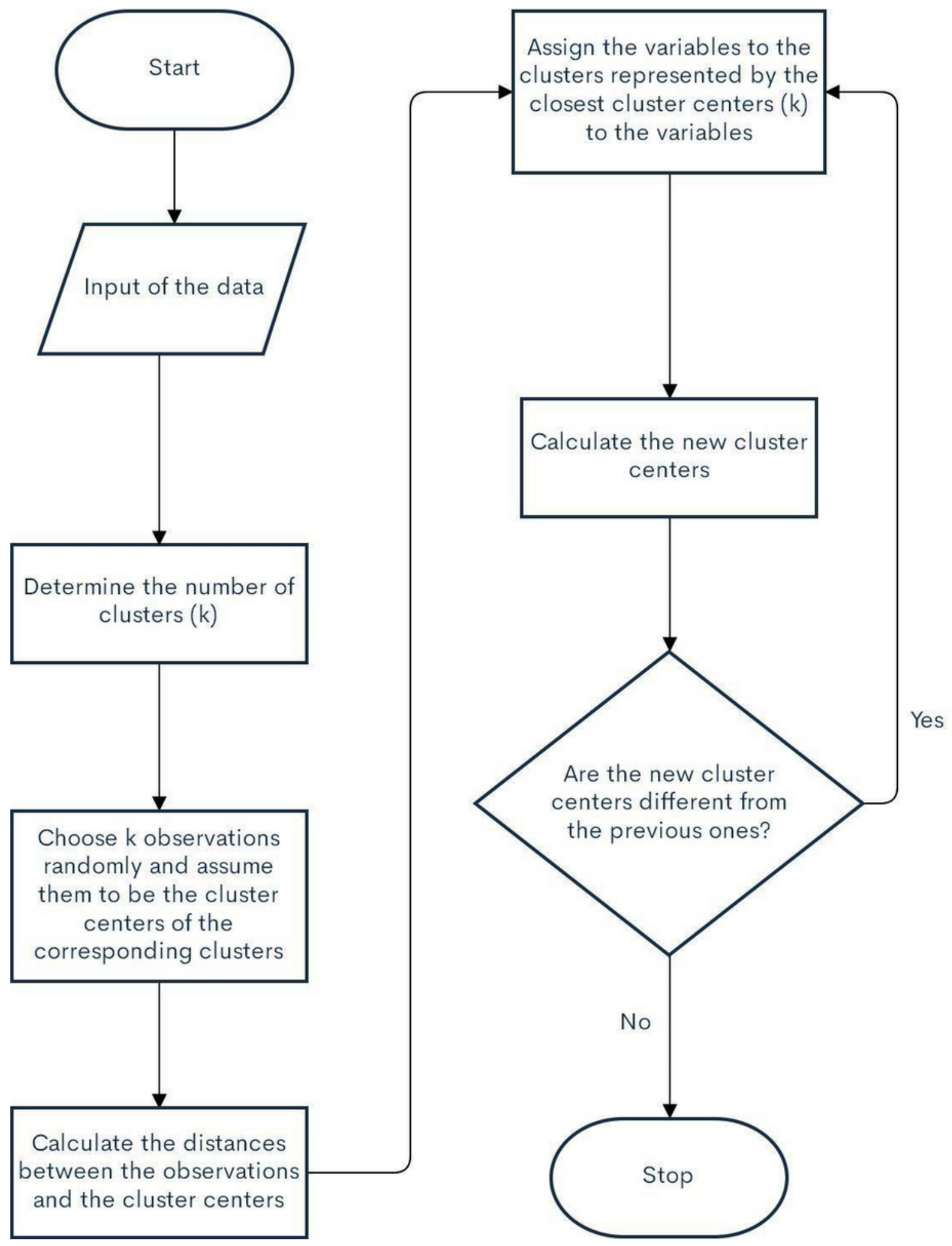

\section{Figure 1}

Flowchart of the k-means clustering algorithm 


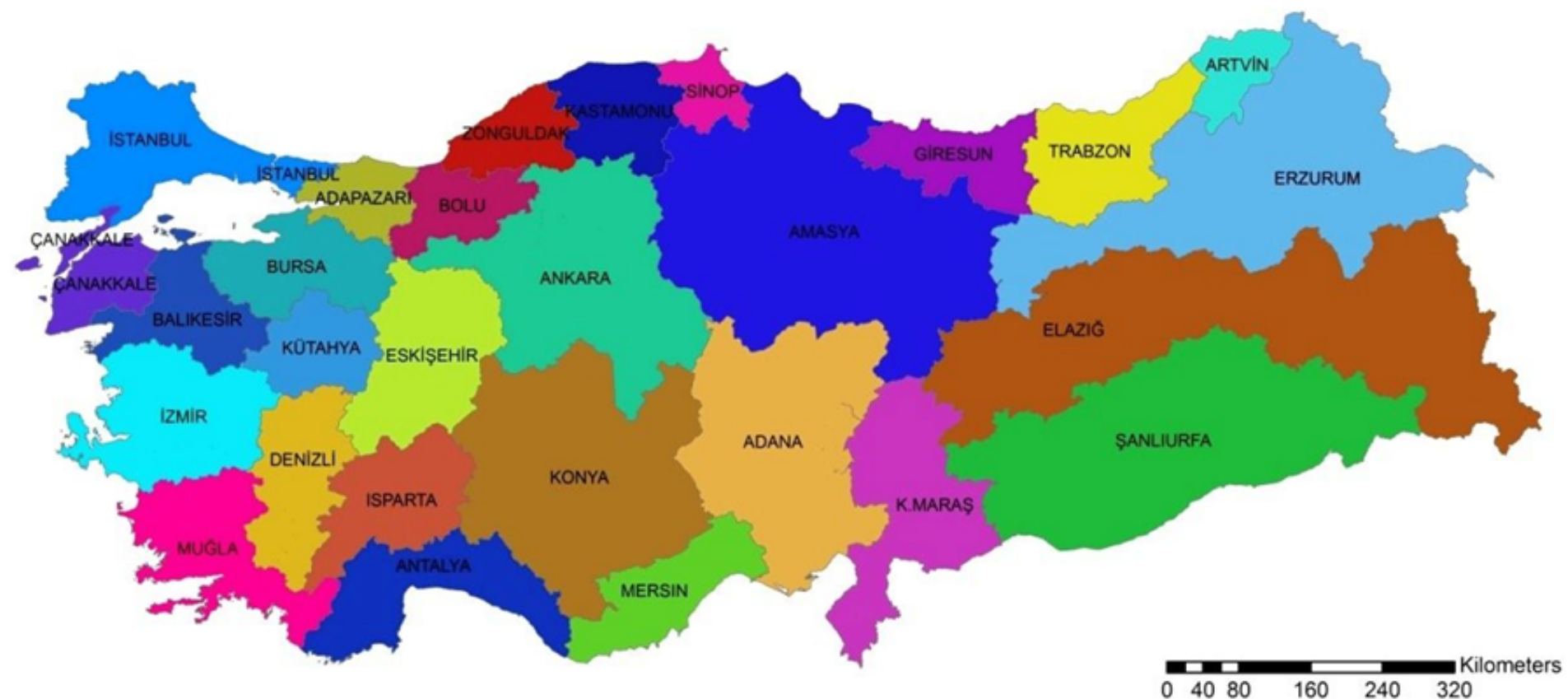

Figure 2

General Directorate of Forestryzones in Turkey(Orman Genel Müdürlüğü - General Directorate of Forestry) 


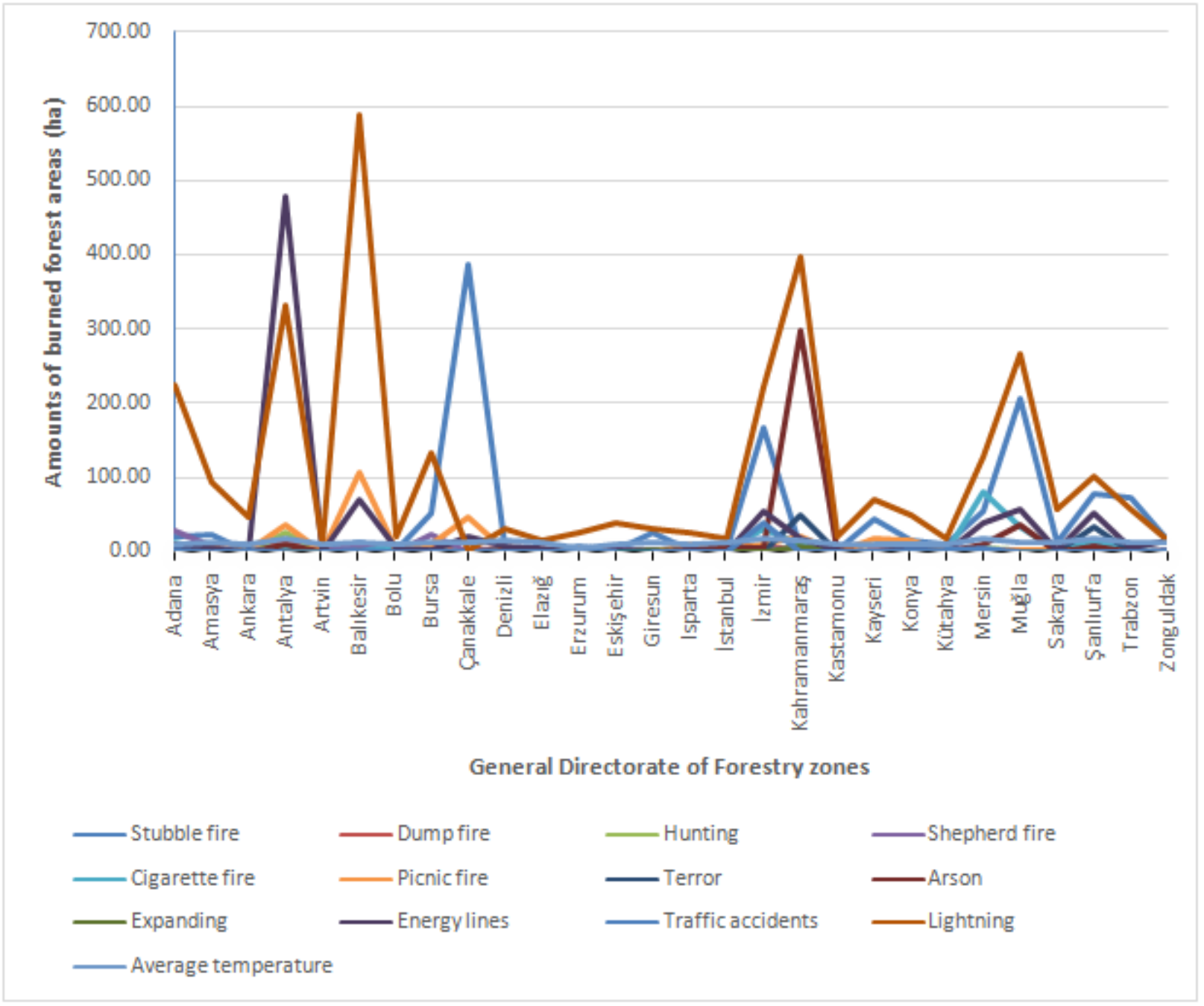

Figure 3

Amounts of burned forest areas due to various causes in the General Directorate of Forestry zones of Turkey(ha) 


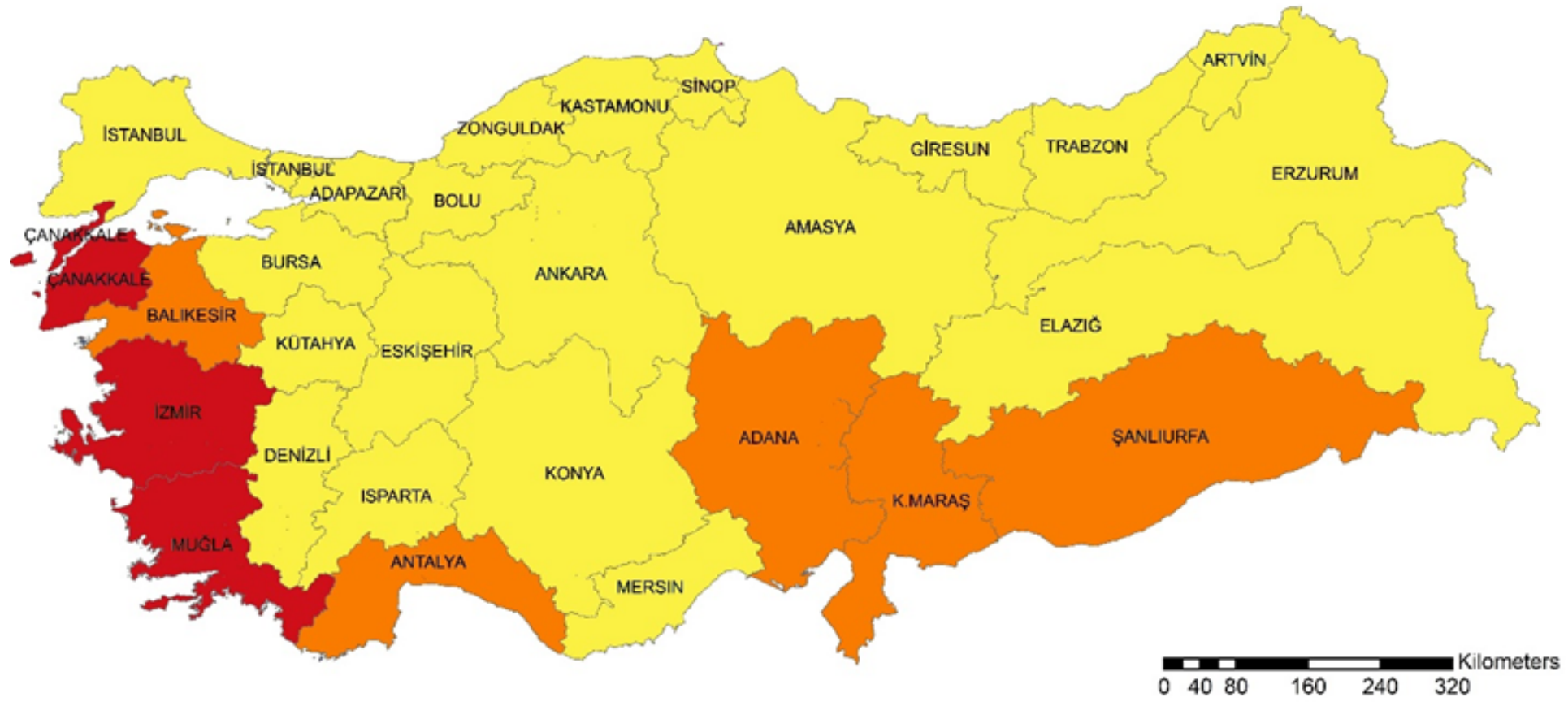

Figure 4

Forest fire risk zone map of Turkey 